Педагогика и психология образования. 2019. № 3

DOI: 10.31862/2500-297X-2019-3-53-61

\title{
Т.Ф. Бородина
}

Елабужский институт (филиал)

Казанского (Приволжского) федерального университета, 423600 г. Елабуга, Республика Татарстан, Российская Федерация

\section{Формирование творческого мышления будущих учителей как проблема профессионального образования}

Статья посвящена проблеме становления творческой личности в условиях вузовского образования. Приводится анализ основных подходов к определению сущности творческого мышления и креативности как его основы. В работе представлены некоторые педагогические технологии, способствующие формированию творческого мышления у студентов педагогических направлений подготовки. Особое внимание уделено обоснованию возможностей языковых дисциплин, в том числе при работе с иноязычным текстом. На основе полученных эмпирическим путем данных автор делает вывод об уровнях сформированности креативности у будущих учителей, особенностях динамики проявления творческого потенциала студентов разных курсов и о влиянии описанных форм и методов обучения на формирование творческого мышления. Дискуссионным продолжает оставаться вопрос об обеспечении в образовательной среде вуза психолого-педагогических и организационных условий формирования творческого мышления студентов.

Ключевые слова: творчество, креативность, творческое мышление, будущий учитель, тип мышления, метод обучения, профессиональное образование

ССЫЛКА НА СТАТЬЮ: Бородина Т.Ф. Формирование творческого мышления будущих учителей как проблема профессионального образования // Педагогика и психология образования. 2019. № 3. C. 53-61. DOI: 10.31862/2500-297X2019-3-53-61 


\section{T. Borodina}

Elabuzhsky Institute (branch) of Kazan (Volga region) Federal University, Yelabuga, Republic of Tatarstan, 423600, Russian Federation

\section{Formation of creative thinking of future teachers as a problem of vocational education}

The article deals with the problems of formation of creativity in the context of higher education. The analysis of main approaches to the definition of creative thinking and creativity is given. The paper presents an overview of pedagogical technologies that help forming creative thinking of future teachers. Special attention is given here to the potential of language disciplines, including work with texts in a foreign language. The author uses the empirically obtained data and makes conclusions about the levels of formation of creativity among future teachers, the differences of creative thinking of the students of different courses and the impact of the described forms and teaching methods on the formation of creative thinking. The question of ensuring psychological, pedagogical and organizational conditions for the formation of students' creative thinking in vocational education continues to be debatable.

Key words: creativity, creative thinking, future teacher, type of thinking, teaching method, vocational education

CITATION: Borodina T.F. Formation of creative thinking of future teachers as a problem of vocational education. Pedagogy and Psychology of Education. 2019. No. 3. Pp. 53-61. DOI: 10.31862/2500-297X-2019-3-53-61

Одним из значимых условий успешной профессиональной деятельности учителя является креативность, которая способствует переходу на новый уровень его профессионализма [4; 12]. Педагогическая деятельность, в основе которой - взаимодействие учителя и обучающихся, не может быть выстроена по одному шаблону, при этом характер педагогического творчества может проявляться как на уровне внедрения инноваций в образовательный процесс, так и на уровне решения конкретных методических задач. 
Творчество как процесс в общенаучном значении представляет собой поэтапное восхождение от формулируемой задачи к реализации ее решения и в этом контексте рассматривается как творческое мышление [11]. При рассмотрении творчества как процесса, направленного на создание нового продукта, креативность представляет собой внутренний потенциал личности, предполагающий выход за рамки известного, отказ от стереотипов в мышлении и деятельности, способность к нестандартному, творческому мышлению [1, с. 522]. В условиях компетентностного подхода творческое мышление, в основе которого лежит креативность как интегральное качество личности, включается в структуру профессиональной компетентности современного учителя, что отражает потребность общества в творческой личности.

Выделение творческого и репродуктивного типов мышления в психологии основано на определении степени новизны продукта, который получает субъект познания. По мнению 3.И. Калмыковой, мышление всегда продуктивно, т.к. его результатом выступает новое знание, но в нем присутствуют как продуктивные, так и репродуктивные компоненты [7].

О.К. Тихомиров под творческим мышлением предлагает понимать вид мышления, который характеризуется созданием субъективно нового продукта, что, в свою очередь, предполагает новообразования в познавательной деятельности (мотивы, цели, оценки, смыслы) [14]. Особенностью творческого мышления является отказ от применения готовых знаний и умений, что свойственно репродуктивному мышлению [10].

А.Ф. Лосев полагает, что мышление всегда представляет собой творчество, т.к. сущность мышления в общем - отражение действительности, которая сама - вечное творчество [9]. Однако отправной точкой настоящего исследования является тезис о выделении мышления творческого и нетворческого, который доказывается в трудах целого ряда ученых $[2 ; 5 ; 7 ; 18]$.

Многими исследователями сущность творческого мышления сводится к проявлению определенных способностей личности: генерировать оригинальные идеи [17], привносить что-то новое [16], осознавать противоречия и формулировать гипотезы в отношении проблемной ситуации [20]. Однако творческое мышление как сложный комплексный феномен не может быть определено по одному признаку. Так, в разное время отечественными и зарубежными психологами были выделены группы ключевых характеристик творческого мышления.

Значимость сформированности творческого мышления в педагогической деятельности можно объяснить посредством представления характерных данному типу мышления признаков и проявлений, которые, 
включаясь в структуру личности учителя, способствуют повышению профессиональной культуры самого учителя и эффективности учебновоспитательного процесса. М.В. Кларин к признакам творческого мышления относит: способность порождать новые идеи и их сочетания для достижения определенной цели; оригинальность конечного продукта, являющегося результатом творческой деятельности внутреннего или внешнего характера [8].

Дж. Гилфорд, являющийся одним из основателей теории креативности, выделяет шесть параметров креативности, которая составляет основу творческого мышления - шесть видов способностей личности, которая мыслит и действует креативно: способность определять и формулировать проблемы, генерировать большое количество проблем, быстро продуцировать разнообразные идеи, создавать отдаленные ассоциации и нестандартные решения, усовершенствовать объект посредством добавления деталей и способность видеть в объекте новые признаки и новые способы его применения [3].

По мнению П. Торренса, мышление и деятельность креативной личности можно оценить по таким критериям, как беглость (генерирование большого количества идей), гибкость (использование разных способов или стратегий решения задачи или проблемы), оригинальность (продуцирование нестандартных решений, идей), разработанность (детальная проработка идеи), сопротивление замыканию (отказ от стереотипов, открытость новому) и абстрактность названия (понимание сути проблемы, приведение образов в словесную форму) [20].

В исследованиях профессионального становления учителя значимость творческого мышления определяется потребностью в продуктивных преобразованиях в рамках педагогической деятельности.

Формирование творчески мыслящего учителя становится важной задачей вузов, реализующих программы подготовки педагогических кадров. К сожалению, одним из существенных недостатков современного профессионального педагогического образования является его слабое влияние на развитие творческого потенциала, креативности будущих учителей. Некоторые аспекты формирования и развития творческого мышления в условиях профессиональной подготовки все еще недостаточно разработаны.

В трудах исследователей представлены основные психолого-педагогические условия, способствующие формированию и развитию творческого мышления студентов, которые условно можно разделить на две группы:

1) субъективные - представляют собой совокупность личностных характеристик, влияющих на формирование креативности будущих 
учителей (личностные качества студентов, их позитивная мотивация творческой деятельности, установка на творчество, профессиональная направленность личности и т.д.);

2) объективные - условия, обеспечивающие возможность целенаправленного педагогического действия и ориентирующие его в соответствии с поставленными целями [6].

С целью выявления сформированности творческого мышления будущих учителей в 2017 г. было проведено тестирование студентов по методике Дж. Брунера [5]. Данная методика подразумевает определение базового типа мышления (предметного, символического, знакового, образного), который влияет на успешность в выбранной профессии, и уровня креативности. Следует отметить, что все студенты, принявшие участие в тестировании, обучались на филологических направлениях подготовки будущих учителей. Этим объяснялось преобладание знакового типа мышления, который характеризует людей с гуманитарным складом ума: 70\% респондентов обладали высоким уровнем сформированности указанного типа мышления (табл. 1).

Таблица 1

\section{Определение базового типа мышления и уровня креативности будущих учителей}

\begin{tabular}{|c|c|c|c|c|c|}
\hline \multirow{2}{*}{$\begin{array}{c}\text { Уровень } \\
\text { проявления } \\
\text { у респондентов }\end{array}$} & \multicolumn{4}{|c|}{ Тип мышления } & \multirow{2}{*}{$\begin{array}{c}\text { Креатив- } \\
\text { ность }\end{array}$} \\
\hline & $\begin{array}{c}\text { Предметное } \\
\text { мышление }\end{array}$ & $\begin{array}{c}\text { Символическое } \\
\text { мышление }\end{array}$ & $\begin{array}{c}\text { Знаковое } \\
\text { мышление }\end{array}$ & $\begin{array}{c}\text { Образное } \\
\text { мышление }\end{array}$ & \\
\hline Низкий, \% & 16 & 27 & 3 & 10 & 7 \\
\hline Средний, \% & 45 & 52 & 27 & 33 & 60 \\
\hline Высокий, \% & 39 & 21 & 70 & 57 & 33 \\
\hline
\end{tabular}

Креативность на высоком уровне проявлялась только у $33 \%$ опрошенных студентов. В процессе изучения динамики проявления креативности будущих учителей на разных этапах профессиональной подготовки было выявлено, что уровень креативности студентов характеризуется заметным снижением к концу обучения (1 курс - 75\%, 2 курс $-50 \%$, 3 курс - 30\%, 4 курс - 33\%). Главной причиной этого представляется выполнение студентами алгоритмизированных заданий, однотипных задач, связанных с поиском однозначных решений, шаблонности процесса обучения. Полученные данные подтверждают необходимость создания в образовательной среде вуза условий для повышения уровней сформированности креативного мышления будущих учителей. 
Процесс формирования творческого мышления студентов заключается в целеустремленном взаимодействии, сотрудничестве преподавателя и студентов в адекватных, специально организованных условиях с применением необходимых форм и методов организации учебно-воспитательного процесса. Анализ научно-методической литературы по изучаемой теме позволяет сделать промежуточные выводы о целесообразности применения определенных методов обучения, которые содействуют повышению креативности будущих учителей в условиях вузовского образования.

Так, правомерно утверждать, что формированию творческого мышления будущего учителя способствует применение в процессе их обучения нетрадиционных форм и методов, инновационных технологий, проведение тренингов, конференций, конкурсов, дискуссий и т.п. Повышению эффективности процесса формирования творческого мышления студентов способствует также реализация принципов проблемного обучения, которое связано с постановкой и решением учебных, научных и профессионально-педагогических задач. Организация проблемного обучения предполагает обеспечение взаимодействия преподавателя и студентов в форме проблемных лекций, практических и семинарских занятий проблемного характера (дискуссии, защита рефератов, деловые игры, решение профессионально-педагогических задач и т.п.).

Исследователями креативности выделены целые группы методов, способствующие формированию профессионального творческого мышления студентов. Так, в классификации, представленной С.Д. Смирновым, обозначены две большие группы таких методов:

1) по способу организации учебной деятельности (к ней относятся структурно-логические, тренинговые и игровые методы);

2) по формирующей направленности (включает методы развития опыта творческой деятельности и методы эмоционального воздействия) [13].

На этапе базовой профессиональной подготовки будущих учителей эффективными являются эвристические методы обучения, стимулирующие развитие творческого потенциала студентов и способствующие формированию их качеств [15].

Представленные методы могут быть успешно реализованы в рамках преподавания языковых дисциплин, в первую очередь на занятиях по иностранному языку. Практический курс иностранного языка обладает большим потенциалом в процессе формирования творческого мышления будущих учителей, т.к. включает творческие задания, применение известной информации в новых (воображаемых) ситуациях, решение проблемных задач и т.д. Особое значение при этом приобретает работа с художественным текстом. 
Исследование роли чтения на развитие личности подтвердило, что досуговое чтение художественной литературы на любом языке положительно влияет на уровень креативности студентов [19]. Было установлено, что студенты, регулярно читающие художественную литературу, в том числе зарубежную и на языке оригинала, чаще обладают высоким уровнем креативности (табл. 2).

Таблица 2

\section{Влияние чтения художественной литературы на уровень креативности будущих учителей}

\begin{tabular}{|l|c|c|c|}
\hline \multirow{2}{*}{$\begin{array}{c}\text { Регулярность чтения } \\
\text { художественной } \\
\text { литературы }\end{array}$} & \multicolumn{2}{|c|}{ Количество респондентов по уровням креативности } \\
\cline { 2 - 4 } & Высокий & Средний & Низкий \\
\hline Регулярно (часто), \% & 37 & 63 & 0 \\
\hline Иногда, \% & 27 & 64 & 9 \\
\hline Очень редко, \% & 16 & 52 & 32 \\
\hline
\end{tabular}

Полученные данные позволяют выдвинуть гипотезу, что степень проявления креативности будущих учителей может повыситься, если обеспечить регулярное чтение художественной литературы на иностранном языке с обязательным применением методов и приемов формирования креативности в процессе анализа и интерпретации прочитанного.

Личный опыт преподавания иностранного языка (в том числе аналитического чтения на иностранном языке) на языковом факультете педагогического вуза позволяет сделать вывод, что в процессе анализа и интерпретации художественного текста студентами, в основном, выполняются задания, направленные на достижение предметных результатов обучения иностранному языку: усвоение новых лексических единиц, формирование навыков диалогической и монологической речи, умений проводить стилистический анализ текста и т.д. При этом задания, связанные с реализацией креативного потенциала студентов и их творческого мышления, составляют не больше $10 \%$. В условиях недостаточного внимания к проблеме формирования креативности будущих учителей такой подход к организации обучения негативно влияет на общее развитие студентов и становление их как самостоятельной творческой личности.

Таким образом, важным представляется разработка целостной системы по формированию творческого мышления будущих учителей в процессе их обучения иностранному языку и методических рекомендаций по организации работы с иноязычным текстом с выполнением заданий, направленных на развитие креативности студентов. 


\section{Библиографический список / References}

1. Башина Т.Ф. Креативность как основа инновационной педагогической деятельности // Молодой ученый. 2013. № 4. C. 521-525. [Bashina T.F. Creativity as a basis for innovative pedagogical activity. Young Scientist. 2013. No. 4. Pp. 521-525. (In Russ.)]

2. Боно Э. де. Развитие мышления: три пятидневных курса. Минск, 2005. [Bono E. de. Razvitie myshleniya: tri pyatidnevnykh kursa [Developing thinking: Three five-day courses]. Minsk, 2005. (In Russ.)]

3. Гилфорд Дж. Три стороны интеллекта // Психология мышления / Под ред. А.М. Матюшкина. М., 1965. С.124-145. [Guilford J.P. Three parties of intelligence. Thinking Psychology. A.M. Matyushkin (ed.). Moscow, 1965. Pp. 124-145. (In Russ.)]

4. Загвязинский В.И. Педагогическое творчество учителя. М., 1987. [Zagvyazinsky V.I. Pedagogicheskoe tvorchestvo uchitelya [Pedagogical works of the teacher]. Moscow, 1987. (In Russ.)]

5. Ильин Е.П. Психология творчества, креативности, одаренности. СПб., 2009. [Ilyin E.P. Psikhologiya tvorchestva, kreativnosti, odarennosti [Psychology of creativity, creativity, endowments]. St. Petersburg, 2009. (In Russ.)]

6. Иванов И.П. Развитие творческого мышления студентов в условиях проблемно-деятельностного обучения: Дис. ... канд. пед. наук. Ставрополь, 2002. [Ivanov I.P. Razvitie tvorcheskogo myshleniya studentov v usloviyakh problemno-deyatelnostnogo obucheniya [Development of creative thinking of students in conditions of problem-activity training]. PhD Diss. Stavropol, 2002. (In Russ.)]

7. Калмыкова 3.И. Продуктивное мышление как основа обучаемости. М., 1981. [Kalmykova Z.I. Produktivnoe myshlenie kak osnova obuchaemosti [Productive thinking as a foundation for learning]. Moscow, 1981. (In Russ.)].

8. Кларин М.В. Инновации в мировой педагогике: обучение на основе исследования, игры и дискуссии: анализ зарубежного опыта. Рига, 1998. [Clarin M.V. Innovatsii v mirovoy pedagogike: obuchenie na osnove issledovaniya, igry i diskussii: analiz zarubezhnogo opyta. [Innovations in global pedagogy: Learning from research, play and discussion. Analyzing foreign experiences] Riga, 1998. (In Russ.)]

9. Лосев А.Ф. Дерзание духа. М., 1989. [Losev A.F. Derzanie dukha [Aspiration of spirit]. Moscow, 1989. (In Russ.)]

10. Общая психология: Словарь // Психологический лексикон. Энциклопедический словарь: В 6 т. / ред.-сост. Л.А. Карпенко; под ред. А.В. Петровского. М., 2005. [General psychology: Dictionary. Psychological Lexicon. Encyclopedia Dictionary. L.A. Karpenko (compiler); A.V. Petrovskiy (ed.). Moscow, 2005. (In Russ.)]

11. Психология креативности / Любарт Т., Мишуру К. и др.; пер. с фр. М., 2009. [Lubart T.I., Mouchiroud C., etc. / Psikhologiya kreativnosti [Psychologie de la créativité ]. Moscow, 2009. (In Russ.)].

12. Сластенин В.А., Подымова Л.С. Педагогика: Инновационная деятельность. М., 1997. [Slastenin V.A., Podymova H.P. Pedagogika: Innovatsionnaya deyatelnost [Pedagogics: Innovative activity]. Moscow, 1997. (In Russ.)] 
13. Смирнов С.Д. Педагогика и психология высшего образования: от деятельности к личности. М., 2005. [Smirnov S.D. Pedagogika i psikhologiya vysshego obrazovaniya: ot deyatelnosti k lichnosti [Pedagogy and psychology of higher education: From activity to personality]. Moscow, 2005. (In Russ.)]

14. Тихомиров О.К. Психология мышления: Учебное пособие для вузов. М., 2005. [Tikhomirov O.K. Psikhologiya myshleniya [Thinking psychology]. Study guide for students. Moscow, 2005. (In Russ.)].

15. Хуторской А.В. Дидактическая эвристика. Теория и технология креативного обучения. М., 2003. [Khutorskoy A.V. Didakticheskaya evristika. Teoriya i tekhnologiya kreativnogo obucheniya [Didactic heuristics. Creative learning theory and technology]. Moscow, 2003. (In Russ.)].

16. Barron F., Harrimgton D. Creativity, intelligence and personality. Ann. Rev. of Psychol. 1981. Vol. 32. Pp. 439-476.

17. Dudek S.Z., Strobel M.G., Runco M.A. Cumulative and proximal influences on the social environment and children's creative potential. Psychol. 1993. Vol. 154. No. 4. Pp. 487-499.

18. Guilford J., Hoepfher R. The analysis of intelligence. N.Y., 1971.

19. Shastina E.M, Shatunova O.V., Borodina T.F. The Role of Reading in the Development of Giftedness in the Context of Globalization and National Identity. Journal of Social Studies Education Research. 2018. No. 9 (1). Pp. 158-167.

20. Torrance P. The search for satori and creativity. Buffalo, 1979.

Статья поступила в редакцию 21.03.2019, принята к публикации 07.06.2019

The article was received on 21.03.2019, accepted for publication 07.06.2019

\section{Сведения об авторе / About the author}

Бородина Татьяна Федоровна - старший преподаватель кафедры немецкой филологии, Елабужский институт (филиал) Казанского (Приволжского) федерального университета

Tatyana F. Borodina - senior lecturer at the Department of the German Philology, Elabuzhsky Institute (branch) of Kazan (Volga region) Federal University

E-mail: tatjanabaschina@yandex.ru 